\title{
Apontamentos para produção de saber e mobilização comunitária: pelas redes de redes
}

\author{
Notes for knowledge production and \\ community mobilization:by networks of networks \\ Notas para la producción de conocimiento y la \\ movilización comunitária: por redes de redes
}

Sergio Portella ${ }^{1}$

Simone Santos Oliveira ${ }^{2}$

\section{Resumo}

PORTELLA, S.; OLIVEIRA, S. S. Apontamentos para produção de saber e mobilização comunitária: pelas redes de redes. Rev. C\&Trópico, v. 45, n. 2, p. 237-255, 2021. DOI: https://doi.org/10.33148/cetropicov45n2(2021)art15

A complexidade dos desafios socioambientais do século XXI aponta para a busca de cooperação, e que conhecimento, gestão e comunidades se articulem de uma maneira inovadora e criativa. A superação da produção de conhecimentos assimétricos, unilaterais e impositivos deve seguir na direção da criação de dispositivos cooperativos que promovam a igualdade, mas também respeitem a diversidade das redes. Apresentamos nosso élan cuidadoso do II Seminário Internacional de Desnaturalização de Desastres, do ponto de vista da mobilização comunitária, que se constitui em um conjunto de reflexões que consideramos fundamental para o enfrentamento da conformação que os nexos sócio-históricos da sociedade brasileira vêm tomando nos últimos anos, que nos transformou em exemplo mundial de desigualdade distributiva de riqueza e que compromete os próprios modos de andar a vida atuais. Estamos diante da necessidade de uma tecnologia social que seja capaz de dar visibilidade às redes comunitárias, estabilizando-as, evitando que, na combinação das redes de gestão e sociotécnicas, se olhe para as redes comunitárias como uma massa informe, desprovida de laços e de saber. Sem isso, nossas dificuldades diante dos desastres, emergências e mudanças climáticas serão devastadoras. Contra-atacamos essa tendência porque todas as vidas importam!

Palavras-chave: Desnaturalização de desastres. mobilização comunitária. Redes. Resistências. Crises ampliadas.

1 Pesquisador da Estratégia Fiocruz para a Agenda 2030/Fundação Oswaldo Cruz; e-mail: spportella@ gmail.com; ORCID: https://orcid.org/0000-0002-1514-7449

2 Pesquisadora permanente do Centro de Estudos em Saúde do Trabalhador e Ecologia Humana/Escola Nacional de Saúde Pública Sergio Arouca/Fundação Oswaldo Cruz; e-mail: sssoliver@gmail.com; ORCID: https://orcid.org/0000-0002-1477-749X 


\section{Abstract}

PORTELLA, S.; OLIVEIRA, S. S. Notes for knowledge production and community mobilization:by networks of networks. Rev. C\&Trópico, v. 45, n. 2, p. 237-255, 2021. DOI: https://doi.org/10.33148/cetropicov45n2(2021)art15

The complexity of the social and environmental challenges of the 21st century points to the search for cooperation and that knowledge, management and communities are articulated in an innovative and creative way. Overcoming the production of asymmetric, unilateral and binding knowledge must move towards the creation of cooperative mechanisms that promote equality, but also respect the diversity of networks. We present our careful élan of the II International Seminar on Disaster Denaturalization, from the point of view of community mobilization, which constitutes a set of reflections that we consider essential for facing the conformation that the socio-historical nexus of Brazilian society has been taking in recent years, which has made us a global example of inequality in the distribution of wealth and which compromises the very ways of living today. We are faced with the need for a social technology that is capable of giving visibility to community networks, stabilizing them, preventing the combination of management and socio-technical networks from looking at community networks as an informed mass, devoid of ties and knowledge. Without it, our difficulties in the face of disasters, emergencies and climate change will be devastating. We counter this trend because all lives matter!

Keywords: Disaster denaturalization. community mobilization. Networks. Resistances. Amplified crises.

\section{Resumen}

PORTELLA, S.; OLIVEIRA, S. S. Notas para la producción de conocimiento y la movilización comunitaria:por redes de redes. Rev. CઐTrópico, v. 45, n. 2, p. 237-255, 2021. DOI: https://doi.org/10.33148/cetropicov45n2(2021)art15

La complejidad de los desafíos sociales y ambientales del siglo XXI apunta a la búsqueda de la cooperación y que el conocimiento, la gestión y las comunidades se articulen de manera innovadora y creativa. La superación de la producción de conocimiento asimétrico, unilateral y vinculante debe avanzar hacia la creación de mecanismos cooperativos que promuevan la igualdad, pero también respeten la diversidad de redes. Presentamos nuestro cuidado impetu del II Seminario Internacional de Desnaturalización de Desastres, desde el punto de vista de la movilización comunitaria, que constituye un conjunto de reflexiones que consideramos imprescindibles para afrontar la conformación que viene tomando el nexo socio-histórico de la sociedad brasileña. Los últimos años, lo que nos ha convertido en un ejemplo global de desigualdad en la distribución de la riqueza y que compromete las propias formas de vida de hoy. Nos enfrentamos a la necesidad de una tecnología social que sea capaz de dar visibilidad a las redes comunitarias, 
estabilizando, evitando que la combinación de redes de gestión y socio-técnicas mire a las redes comunitarias como una masa informada, desprovista de vínculos y conocimientos. Sin él, nuestras dificultades frente a desastres, emergencias y cambio climático serán devastadoras. ¡Contrarrestamos esta tendencia porque todas las vidas importan!

Palabras clave: Desnaturalización de desastres. Movilización comunitaria. Redes. Resistencias. Crisis amplificadas.

A terra dá e a terra quer... o melhor lugar para se guardar os peixes é no rio... o melhor lugar para se guardar as batatas é na terra... o melhor lugar para se guardar os frutos é nas árvores... não é feio pedir, pedir é ruim, feio é deixar pedir... tudo vai acabar como começou... devemos transformar as armas dos inimigos em nossas defesas...Com os sentimentos de quem está se preparando para um novo começo, eu faço uma pausa dizendo que: Nós nascemos nos ventres das mães mulheres para aparecermos na terra...E nascemos no ventre da terra para aparecermos na ancestralidade! Vivas, porque todas as vidas importam! (BISPO, 2020, p. 252-254)

\section{Introdução}

A trama de redes se confunde hoje com a superfície da Terra. Se somos algo do ponto-de-vista ontológico, somos redes. Sob qualquer ponto de vista, a vida - qualquer vida - é rede! E assim se manifesta: rede de relações. A principal consequência dessa afirmação de que devemos somente às redes a nossa existência, está expressa no texto de Antonio Bispo, em epígrafe: Todas as vidas importam! Com essa afirmação ele também abriu a mesa de encerramento do II Seminário Internacional de Desnaturalização de Desastres e Mobilização Comunitária de 4 a 8 de outubro de 2021. A saudação em sua sabedoria quilombola se torna assim uma potencialização das relações da vida, aceitando-as e buscando a superação de desigualdades, iniquidades, injustiças, assimetrias que colocam as redes da vida em risco de sufocamento e invisibilidade. Em sua sabedoria, Antonio Bispo aponta a necessidade de superarmos a dicotomia progressista e excludente da separação entre natureza e humanidade, natureza e cultura, dicotomia fundadora da própria etnologia (LÉVI-STRAUSS, 2004), ciência criada para lidar com a diferença de povos do sul e os colonizar: "precisamos desumanizar, os animais, e precisamos animalizar, a humanidade”, reage Nego Bispo. E, quando afirmamos durante todo o II Seminário, a necessidade de desnaturalizar os desastres, estamos alinhados com esse programa quilombola. Isso também porque a complexidade dos desafios socioambientais do século XXI aponta para a busca de cooperação e, no caso, das problemáticas de Gestão de Risco de Desastres (GRD) exige que conhecimento, gestão e comunidades se articulem de uma maneira inovadora e criativa. A superação 
da produção de conhecimentos assimétricos, unilaterais e impositivos deve seguir na direção da criação de dispositivos cooperativos que promovam a igualdade, mas também respeitem a diversidade das redes. Diversidade de compartilhamento favorecido, imediatamente, pelo desenvolvimento de tecnologias de comunicação informacionais, que irão se constituir em uma forma prevalente de organização social e de produção de conhecimento em forma de rede digital para enfrentamento da complexidade das problemáticas atuais - p.ex. questões relativas ao risco ambiental e industrial, a segurança alimentar, as epidemias, ao racismo ambiental.

Pelas nossas experiências de pesquisa-intervenção no acompanhamento de comunidades que vivenciaram desastres de origem natural (cidades serranas em 2011) ou tecnológicas (como os rompimentos de barragens e seus riscos nos municípios de Mariana, Brumadinho e Ouro Preto), apresentamos aqui nosso élan cuidadoso do II Seminário Internacional de Desnaturalização de Desastres, do ponto de vista da mobilização comunitária, que se constitui em um conjunto de reflexões que consideramos fundamental para o enfrentamento da conformação que os nexos sócios-históricos da sociedade brasileira vêm tomando nos últimos anos, que nos transformou em exemplo mundial de desigualdade distributiva de riqueza e que compromete os próprios modos de andar a vida atuais. Conformação que ficou explicitada pela crise sócio sanitária da pandemia Covid-19 com seus mais de 600 mil mortos, equivalente a 600 megadesastres serranos diários em um período de dois anos, algo em termos de genocídio quase comparável - e ainda assim menor -, ao período que seguiu à conquista das terras de Abya Ayala (VIEZZER; GRONDIN, 2021) pelos povos ibéricos submetendo os povos originários e os povos negros deslocados e escravizados.

Partimos da discussão acerca do conceito de desastre desenvolvido pela sociologia do desastre latino-americana ${ }^{3}$, que tem problematizado a definição de desastre natural, compreendendo-o como processo socialmente construído, com dimensões objetivas e subjetivas, alargando-o para além do espaço-tempo da agudeza dos acontecimentos trágicos ao considerar seus nexos sócio-históricos determinantes.

É a malha de vulnerabilidades territoriais, expressão de desigualdades e iniquidades, que determina não só a possibilidade de desastres, mas também a sua intensidade e gravidade, que expressam muito mais o modelo de desenvolvimento do que os seus chamados eventos detonadores. Essa malha é ainda a expressão de como as relações sociais estão organizadas hierarquicamente e por superposição de seus componentes. E são as relações hierarquizadas em suas desigualdades, a última determinação dos desastres, dobradas e redobradas em sua interseccionalidade de classe, gênero e raça.

No percurso de nossos estudos, nos deparamos com a importância dessas conformações de redes (PORTELLA; OLIVEIRA; DUTRA, 2015) no processo de reconstrução apontando para a premência de uma rede de Desnaturalização dos desastres, espaço de expressão de um conjunto de outras redes comunitárias, acadêmicas, profissionais, e de movimentos sociais. Buscamos, dessa experiência, em que o II Seminário é a sua mais pura expressão, sistematizar suas consequentes reflexões ao pensar como

3 Ver nesta Ciência \& Trópico os artigos de Allan Lavel, Henri Acserald, Norma Valencio e Claudia Natenzon. 
as redes podem contribuir para a execução virtuosa do ciclo de GRD de prevenção, resposta e recuperação, numa perspectiva de resiliência comunitária em sinergia com os territórios vulnerabilizados.

Impacto de um fenômeno natural extremo ou intenso sobre um sistema social, e que causa sérios danos e prejuízos que excedem a capacidade dos afetados em conviver com o impacto, os desastres são acontecimentos drásticos, que mesclam aspectos sociais - objetivos, subjetivos e simbólicos - da vida de pessoas e dos seus lugares (de moradia, de trabalho, de circulação) e que se estabelecem nas suas singularidades territoriais em função direta ao modo de vida e de desenvolvimento ali estabelecido. $\mathrm{Ou}$, parafraseando Milton Santos (2005), é intimamente dependente do sistema territorializado de objetos e de ações, a tal ponto que tornam os eventos detonadores expressão desse sistema. Assim, relações sócio-históricas de desenvolvimento de uma comunidade são o meio que determina a resiliência comunitária presente em sua possível recuperação e reconstrução. E seus processos de vulnerabilização, que geram figuras assustadoras como o racismo ambiental, a sua extensão de durabilidade temporal.

Para avaliar o desenvolvimento humano, seguimos Schwartz (2019), utilizando os conceitos de aderência e desaderência dos conhecimentos utilizados para promover o desenvolvimento de produção-consumo de um determinado território geolocalizado na sua interação com os mercados mais ou menos globalizados. Produzir desastres e crises sanitárias, é assim uma das medidas desse desenvolvimento. Promover o bem-estar e a saúde, da população de um determinado território, outra. Mas, nas inúmeras vezes, que acompanhamos situações de desastres, entramos na discussão do desenvolvimento humano, pela porta dos fundos da economia de produção-consumo, pelos desastres e pelas crises, por entre as ruínas e sofrimentos provocados pelas decisões de desenvolvimento que geraram territórios vulneráveis. Frutos de uma lógica forjada nos chãos das fábricas fordistas e extrapolada para cada área de organização da sociedade dita ocidental: escolas, serviços, hospitais, instituições de pesquisa, empresas de construção e infraestrutura, todas respondem a uma dupla delegação: a direção da produção-consumo nas mãos dos coletivos donos do capital e a operação dessa mesma produção, que exige toda uma sociedade em seu entorno, nas mãos dos coletivos de gerentes e mestres de produção, controladores dos métodos e técnicas, com seus espelhos nas gestões das cidades e dos campos. Poder-saber, gestão-conhecimento é a dupla delegação (CALLON et al. 2013). O seu deslocamento com relação aos trabalhadores e cidadãos gera uma organização em torno da produção-consumo mais aderente ou desaderente com relação ao território em que se estabelece. É daí que surgem todos os sofrimentos, mazelas e perigos críticos de nosso atual desenvolvimento, em que os efeitos evidentes das mudanças climáticas e a própria pandemia são seus limites mais gerais como evidenciado no último relatório do IPCC (IPCC, 2021). Quanto mais desaderente é a dupla delegação da produção social, com relação a sua população e ao território em que se realiza, mais riscos tendenciais temos, mais perigos a desastres e crises sanitárias, e criticidade socioambiental, condicionadas por vulnerabilidades em uma malha sofisticada e complexa de vulnerabilidades territoriais em que o racismo ambiental é sua face mais perversa. 
Colocamos aqui o esforço de pensar dispositivos capazes de diminuir a desaderência em prol de maior aderência territorial, privilegiando o saber local para buscar prevenir ou superar essas adversidades advindas do modelo de desenvolvimento dominante, principalmente em territórios do sul global. Nesse sentido, é que o sofrimento social e psíquico na singularidade territorial de um evento extremo, confere às comunidades que o vivenciam a legitimidade de dizer privilegiadamente o que foi que se passou com elas. No entanto, esse sofrimento social comunitário e a sabedoria resultante de sua vivência tendem a ser invisibilizados pelas redes de gestão e sociotécnicas, que se combinam nessa dominação e desqualificam as redes comunitárias.

Pelas redes e nas redes é que teremos a batalha da inclusão e da exclusão de bilhões de seres humanos, em ondas de inovação e de criação de novas formas de vida, aponta Boaventura Santos (2007). Esse princípio tem seu espaço hoje representado pelas web-redes, na compreensão de que a mobilização comunitária e um novo regime de saber devem emergir dessa ação em redes, desses encontros de encontros, dessa rede de redes.

\section{Por uma pedagogia das redes}

Seguindo Nobert Elias (1994), devemos considerar que os seres humanos vivem interagindo em redes ou teias de dependências mútuas. Elias critica a ideia do homem como personalidade indepedente e isolada e acrescenta que devemos reconhecer que a personalidade é sempre orientada para o outro, gerando uma interação, uma interdependência, uma configuração. Esse conceito de configuração pode ser compreendido como formação social ou rede de interação permanente, em que os indivíduos ou grupos estão ligados uns aos outros por um modo específico de dependências recíprocas. Processos de agrupamentos por meio de inúmeras cadeias de relacionamentos, nas quais os equilíbrios de poder tendem a determinar a conduta das pessoas. A configuração é, assim, um padrão mutável no jogo das relações, cuja interdependência supõe um entrelaçamento flexível em constante movimento (ELIAS, 1994).

Na resposta a um desastre - para focarmos em nossa porta dos fundos -, há o surgimento de muitas redes de solidariedade em função das necessidades serem múltiplas e os recursos estarem desorganizados, em que a interdependência das redes é intenso. Depois temos um movimento de retração. As redes profissionais, acadêmicas, governamentais e não governamentais, mais rígidas e consolidadas, dominam a cena da recuperação. As redes espontâneas, em geral ligadas à disposição solidária da população, perdem a força do momento da resposta e são capturadas.

Em geral, as redes se consolidam graças a atores-chaves, verdadeiros nós de rede, que são integrantes de muitas redes ao mesmo tempo, e de todos os tipos, espontâneas e mais rígidas, ligadas a instituições e movimentos, ou que partilham um espaço híbrido de espontaneidade com rigidez. Tais redes se consolidam justamente pela imbricação de redes que inicialmente é oferecida por esses atores-chaves. E as redes podem escapar do seu esfarelamento. Quando esses movimentos não se esfarelam e avançam, Castells (2013) registra que em todos os casos que estudou, que a 
passagem da solidariedade à implementação de mudança depende da permeabilidade do sistema político estatal formal, e de suas instituições, às demandas do movimento, e dessas partes, assim, negociarem. Por outro lado, o reconhecimento dessas demandas pelo poder instituído depende da possível contribuição dos movimentos às agendas pré-estabelecidas pelos atores políticos.

Por isso, destaca Castells (2013), se o objetivo é estabilizar redes comunitárias, a influência do movimento sobre programas de governo é limitada e é preciso se estar atento a essa limitação. Isso, principalmente, porque um componente de uma rede é componente de muitas redes; e, assim, a rede-movimento carrega em si a potencialidade de todas as outras redes de que seu componente faz parte.

Apesar de hoje, o fenômeno das redes estar mimetizado pelo sistema digital da internet, devemos considerar que as redes sempre existiram e que elas sempre foram determinantes para as ações humanas. Essa consideração original dos trabalhos de Bruno Latour (2001) sobre as redes das ciências e sociotécnicas levou o seu grupo de pesquisadores a criar a Teoria do Ator-Rede, que seria justamente a compreensão de que sempre o que se teve foram redes, redes formadas por relações, por vínculos, laços tecidos um a um e singularmente. Daí que Latour irá considerar a rede científica uma das redes mais estáveis dos últimos anos pela generalidade e força de seus vínculos conectados um a um. Dessa forma, quando entramos em um ambiente que possui padrões e identidades, não devemos explicar a identidade pela própria identidade, mas sim explicar como a partir da diferença, surge isso que parece não ser diferente, mas igual. Grandes abstrações, para Latour, como sociedade, economia, natureza, escondem a sua origem em rede. Essas grandes abstrações são efeitos óticos de infinitas relações em rede que se espelham e, assim, se multiplicam. Basta olhar de perto para vermos que a existência dessas grandes abstrações são o que são: condensações linguísticas de uma intrincada rede. A simplicidade do laço em rede é então substituída por leis, no pensamento científico dominante, que estariam acima dos próprios laços de sua constituição. Não os reconhecer é o primeiro passo para se aceitar como natural a assimetria de saber, e promover discursos esotéricos-científicos para iniciados, produtor de ignorâncias comunitárias (SANTOS, 2007).

Essa distorção de perspectiva, segundo Deleuze e Guattari (1996), gera um tipo de racionalidade que definem como o pensamento-árvore, dominante, em contraposição à racionalidade do pensamento-arbusto, que chamam rizoma. No pensamento-árvore e seus congêneres teóricos e sociotécnicos, busca-se a filiação, indicado pela verticalidade do tronco, cujo modelo da dupla delegação é uma de suas mais importantes consequências. No pensamento-arbusto, tem-se o alinhamento singular em rede.

As características desses laços estabelecidos por dentro de um fluxo vivo de desejos e crenças, Latour foi buscar em Gabriel Tarde (1843-1904). Tarde (2011), um dos precursores da sociologia, relegado a um longo esquecimento em função das controvérsias que estabeleceu como Emile Durkheim (1858-1917), justamente porque discordava que o social fosse maior que a rede de laços produzida um a um, e que só pudesse ser explicado por um mesmo ente social, abstrato, o fato social como o queria 
Durkheim. Para Tarde, a sociedade era o efeito da repetição de seus laços, e eram esses em suas composições únicas que deveriam explicar aquele algo que parecia ser um tecido pronto e acabado: nada, que de longe parece ser algo macro e unificado, resiste à aproximação do olhar. Nessa aproximação íntima, pode-se se ver que o macro é sempre composto pelo micro de uma maneira radical. Segundo Tarde (2011), só existe o micro, a única forma da realidade.

Assim, a sociedade se produz por espelhamento em seu fluxo de desejo e crença. Esse fluxo conforma e é conformado pelos laços de indivíduo para indivíduo, estabelecendo redes. Concordamos, então, que as redes de hoje são as redes de ontem, mas como se diferenciaram? Através da associação com outra rede, uma extensa e capilar rede de não-humanos, a rede planetária digital, a internet. Na inovação dessas redes, temos velocidade que transforma tudo em on-line, isto é, em tempo presente; escala que conecta tudo e todos sem discriminação e visibilidade que faz o direito de igualdade de estar visível, como qualquer um ou como qualquer rede, a qualidade de todos! Por causa da velocidade de processamento dos dados, pela escala de conexão de bilhões de humanos e não humanos, e a democracia da visibilidade digital em rede, um laço virtual hoje é tão próximo como um laço real vizinho de nossas mãos, nos quais as pessoas se olham - vivemos isso intensamente na pandemia de Covid 19! E esse desenvolvimento ainda está longe de se estabilizar com inovações crescentes e automultiplicadoras como, por exemplo, a virtualização do olhar real pelas pequenas câmeras dos celulares. Esse próximo virtual possui uma possibilidade espacial infinita por sua conexão em rede, onde combatê-lo, tática de alguns tipos de poder-visão, fica quase-impossível: a destruição de uma rede está cada vez mais próxima da sua reconstrução, pela sua capacidade de viralização. O ser viral da rede, ou o ser nano da rede, não lhe dá limite ou contorno definitivo, justamente porque suas partes têm infinitas possibilidades de reencaixe, centrais ou periféricas, nucleares ou fronteiriças: isto é, não há gênero nas redes atuais, a sua capacidade rizomática se expande exponencialmente, ou melhor, viraliza.

Rizoma vem de raiz. Os arbustos têm formato de raiz. E também as copas das árvores têm formato de raiz. Apenas uma pequena parte dos vegetais e das árvores tem o formato esguio e vertical dos caules. Mas seria correto dizer que existem imensos vazios rizomáticos entre a rede-solo e o mundo das redes-copas, apenas conectados por caules?

Não existe espaço vazio em ambientes vivos. Precisamos construir essa questão de maneira mais precisa: Por que a complexa rede parece invisível aos olhos treinados a valorizar caules? Sem a rede a vida não seria possível. Nenhum caule cresce no vazio, conectando duas redes: a raiz e a copa! Quem é afiliado ao pensamento-caule, quer ver apenas a fortaleza do caule, a sua elegante verticalidade. No entanto, mesmo em sistemas florestais, já se sabe que um rizoma infinito por debaixo da terra conecta todas as árvores em uma floresta ou bosque, transformando-as em um sistema único (SIMARD, 2010). Isso sem considerar as redes-animais de insetos, bactérias, fungos, pássaros e mamíferos. Mesmo sistemas sócio-técnicos são impossíveis de funcionarem sem estar 
em redes. Mesmo a esteira de Ford, ou o pensamento estruturante de Taylor ${ }^{4}$, definidas como árvores, por excelência, só são possíveis porque ali existe uma enorme rede-rizoma conectando humanos e não-humanos, para utilizar a linguagem de Latour (2001). Nesse sentido, mais do que um caule realmente, o que nos é imposto é uma visão, que recorta um caule, que vê um caule. Nessa visão, o que não estamos observando? O que estamos observando que faz não vermos o resto? O que vemos demais nos é imposto pela violência conhecimento-árvore, o sistema das filiações e trocas privilegiadas de valores - onde circulam constrangidos vários tipos de valores, assegurados pela assimetria do saber, produtora de ignorantes, desiguais, excluídos e, por fim, invisíveis (e assim as redes ficam ocultas na essencialidade das ciências humanas dominante).

Essa associação entre determinado poder com determinada visão, gerando um tipo de saber, Foucault (2009) chama do encontro entre a hegemonia e sua aleturgia. Para ele, não há condição de existência de nenhuma hegemonia, no sentido gramsciano $^{5}$, sem o exercício de uma aleturgia, de uma expressão da verdade associada ao poder. A produção da verdade na consciência dos indivíduos pelos procedimentos lógicos e experimentais, não é, depois de tudo, mais que uma das formas possíveis desse exercício para proferir a verdade. A ciência, o conhecimento objetivo, é somente um momento possível na história ocidental de todas essas formas pelas quais se pode manifestar o verdadeiro. Isto é, a ritualização do pronunciamento da verdade do exercício da hegemonia hoje é oferecida pela ciência assimétrica: a aleturgia produtora da visão dos caules, associada a hegemonia capitalista, que opera no micro (e só existe micro) na forma da dupla delegação. Tudo que se chama de macro, são redes dominantes e colonizadoras disfarçadas, que buscam o controle das infinitas redes que as sustentam.

4 A esteira de Ford é um modo simplificado de se referir aos sistemas de linha de produção e gestão desenvolvidos em 1913 pelo empresário americano Henry Ford (1863-1947). Ford cria a primeira linha de montagem automatizada e revoluciona a indústria automobilística. Ele se baseia nos princípios de rotinização e simplificação de Frederick Taylor (1856-1915), engenheiro americano que desenvolveu administração científica do trabalho. A administração científica ou taylorismo caracteriza-se pela ênfase nas tarefas, objetivando o aumento da eficiência operacional da produção. A metodologia de Taylor era caracterizada pelos estudos de tempos por tarefa a partir da observação do trabalho realizado por operários. Sistematizado o melhor tempo e a melhor realização para cada tarefa, a execução da tarefa customizada era exigida dos trabalhadores. Esse método é posteriormente generalizado para todas as indústrias e mais tarde contamina o modo de organização da sociedade ocidental em qualquer área. A aplicação mais famosa deste método é justamente as linhas de produção em massa de Ford. Os Ford-T eram montados em esteiras rolantes, sem praticamente nenhuma movimentação exigida operário, a não aquele inerente a tarefa que devi realizar. A eliminação do movimento inútil otimizava a produção ao dar a cada operário a responsabilidade de uma operação simples. A qualificação dos trabalhadores no sistema de Ford é quase nenhuma e essa passa a ser um ideal da relação conhecimento-gestão.

5 Antonio Gramsci (1891-1937) importante teórico marxista que escreveu sobre a determinação da estrutura econômica da sociedade em relação à superestrutura cultural. Ele flexibiliza a determinação econômica com relação à cultura e a esta dá uma certa autonomia e complementaridade a estrutura econômica. Escreveu grande parte da sua obra nas prisões do regime fascista de Mussolini e desenvolveu conceitos famosos como intelectual orgânico, hegemonia cultural e bloco histórico de uma determinada época. Bloco Histórico, para Gramsci, seria a unidade entre estrutura econômica e superestrutura social. Esta unidade seria dominada pela hegemonia cultural de determinada classe social. O conceito de hegemonia relativiza a ideia de dominação absoluta da cultura por determinada classe social e possibilita a emergência, por exemplo, do intelectual orgânico que estaria a serviço das classes dominadas, apesar da sua formação ter sido feita por dentro da cultura hegemônica. 
Lembramos sempre da afirmação de Eduardo Viveiros de Castro no prefácio de $A$ Queda do Céu (KOPENAWA, 2016, p.18): Não é a selva que é tutelada e protegida pelo Estado. É o Estado que tem a sua condição de existência possibilitada pela floresta! Situação idêntica da esteira de Ford que só era possível pela extensa rede de coletivos de trabalhadores, que a tornava viva e eficiente.

Nessa dupla delegação, estamos ao lado das redes que são exploradas e invisibilizadas em sua potência: de poder, de saber, de existência, as micro redes comunitárias. Mas não é possível mudar sem conversar, já que a violência histórica das redes sociotécnicas e de gestão está caminhando para recrusdecimento inesperado nos últimos anos disfarçados muitas vezes de naturais mudanças climáticas. Todas as vidas importam, repetimos em uníssono a Nego Bispo.

Rede-movimento, rede sociais, redes profissionais, redes institucionais, redes pessoais. As redes são híbridas em suas potencialidades e hoje, têm a sua expressão assegurada nas redes via internet com todas as possibilidades que seus encontros possibilitam, ao contribuírem para: compensar a falta de formação tradicional de seus integrantes; superar a falta de equipamentos e recursos; reduzir a dispersão dos esforços e a falta de estímulo. As redes via WEB cumprem, agora, muitas funções que antes fazíamos pessoalmente e a partir de longa cooperação e permitem ousar o enfrentamento de problemáticas de maior complexidade, unindo vontades distantes, conhecimentos invisíveis, e capacidades desconhecidas. E é por isso que afirmamos que estão nelas depositadas nossas esperanças de criação de novas formas de mobilização social e novos regimes de produção de saberes cada vez mais democráticos e solidários (AGUNIN; HIDALGO; NATENZON, 2010).

\section{II Seminário Internacional de Desnaturalização}

Se continuarmos entendendo o mundo assim, viveremos sempre produzindo incidentes, terríveis incidentes engajados em nome e em defesa do progresso, da evolução e só teremos a banalização e o desprezo pela vida como horizonte de expectativa. Digo isso porque o que escolhemos comer, vestir, fazer, plantar, criar tem relação com tudo isso, mas, ao invés de ser habitado, o mundo passou a ser disputado, como se nós tivéssemos recebido o mundo para isso: para uma grande e infinita disputa. Quando defendo que precisamos voltar a sonhar é porque precisamos acreditar na criação de uma inteligência sutil, movente, para permitir que a vida, em sua diferença, coexista (KRENAK, 2020, P. 20-22).

As reflexões com base no desastre da região serrana (PORTELLA; NUES, 2014) apontam o desafio da dupla delegação como obstáculo na recuperação das cidades, na sua dimensão objetiva e subjetiva: há a necessidade de desenvolvimento de dispositivos contra a invisibilidade e volatilidade das redes comunitárias, apontando para uma 
rede de redes na perspectiva da desnaturalização dos desastres. No enfrentamento da relação comunidade/profissionais/academia, para ampliar o poder de agir da comunidade, verificamos a necessidade da utilização de instrumentos/dispositivos que mediatizem essa relação e sua transformação do qual o II Seminário faz parte e assim foi pensado. Sonhado, diria Ailton Krenak.

Tecer os fios para a constituição dessa rede de desnaturalização dos desastres surgiu na urgência das necessidades dos afetados do desastre de 2011, e dos pesquisadores e profissionais que buscam o reforço da mobilização. Essa tessitura se desenvolveu e se estruturou a partir de diversos encontros na região serrana e pela realização de oficinas nas instituições formadoras. Essas ações culminaram no Seminário Desnaturalização dos desastres e mobilização comunitária: novo regime de produção de saber, em 15 e 16 de outubro de 2015, na Fiocruz/RJ, com a premissa de que desnaturalizar a concepção dos desastres e fortalecer os movimentos comunitários são condição essencial para que novos regimes de produção do saber possam emergir (OLIVEIRA et al, 2016). As discussões do seminário foram publicadas no dossiê da Revista Ciência \& Trópico 40, e que agora se repete em movimento, parcerias e redes na sua segunda edição no II Seminário de Desnaturalização de Desastres e Mobilização Comunitária: crises ampliadas, redes e resistências.

Esses encontros visam além de favorecer as trocas, fortalecer e ampliar as ações das redes, híbridas, sem contornos definidos que necessitam de dispositivos que sustentem os seus movimentos territorializados. Possibilitar o encontro entre gestão, academia e movimentos comunitários num esforço de mapear e tornar visível todas as redes. Mas, se fundamental, em determinado nível de organização e comunicação, é no microcomunitário que a sua sustentabilidade é mais crítica e exige uma dedicação para manter o seu crescimento e vigor vital.

\section{Dispositivo para construção de uma Comunidade de Pesquisa- Intervenção}

Latour (2012) define o social como um fluxo visível apenas quando se fazem novas associações. Essas associações ficam visíveis graças às relações que estabelecem com objetos ao seu redor. Mas, para Latour, os objetos parecem associar-se uns com os outros e com laços sociais só momentaneamente, em situações especiais. Nesses momentos, não só os objetos modificam o curso do fluxo social, como o tornam visível em suas características e correlações. Quatro situações são destacadas por Latour: as inovações cientificas e tecnológicas; as novas tecnologias, ao serem utilizadas pela primeira vez pelos usuários; a memória por meio de relatórios, arquivos e documentos dessas mesmas controvérsias sociotécnicas; e, por fim, as situações oferecidas por desastres, acidentes, rupturas e golpes. Nosso caso, especificamente.

Quando, então, o fluxo do social fica visível, é preciso bidimensioná-lo, achatá-lo, planeá-lo (torná-lo plano), torná-lo uma carta (cartografar). Aqui, usando os fatos científicos para demonstrar como ele realiza esse achatamento, Latour (2001) constrói 
um modelo explicativo de redes que ganha no plano a forma de estrela (Figura 1): ela descreve as "diferentes preocupações que todo pesquisador tem de alimentar ao mesmo tempo caso queira ser bom cientista"; em outras palavras, ela descreve "o sistema circulatório encarregado de manter vivos fatos científicos". Ele poderia ser descrito como cinco tipos de atividades, cinco circuitos: dos instrumentos, dos colegas, dos aliados, do público e dos "vínculos".

Figura 1: Circulação e redes da ciência

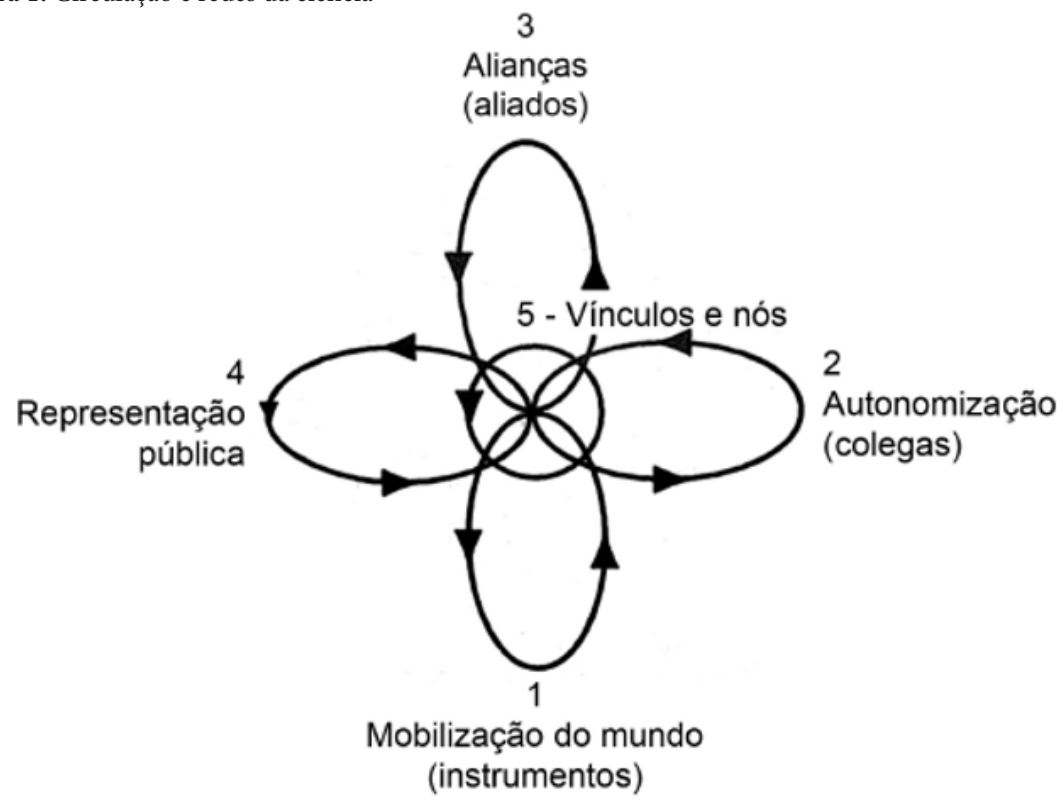

Figura 1 Latour, 2001, p. 118.

O primeiro circuito, dos instrumentos, a mobilização do mundo, trata de expedições, levantamentos e dos locais nos quais todos esses objetos do mundo assim mobilizados estão reunidos e contidos. O segundo circuito, os colegas, a autonomização, trata da história das profissões e disciplinas e das próprias instituições científicas (organizações, recursos, estatutos, regulamentos para manter juntos os colegas). O terceiro circuito, das alianças, trata da necessária mobilização de grupos grandes, ricos e competentes, capazes de garantir o aperfeiçoamento do trabalho científico. O quarto circuito é o da representação pública ou o da socialização maciça de novos objetos no coletivo, sem abalar o sistema normal de crenças, seja um átomo, radares ou grupos sociais. Por fim, o quinto circuito desse vasto sistema circulatório é o próprio conteúdo científico, o coração palpitante propriamente. Todo esse sistema está vivo, sendo que nenhuma de suas partes é dispensável; todos os circuitos funcionando ao mesmo 
tempo são um evento único, vivo, encadeado, total. O que vemos aqui aplicado para a rede científica, podemos aplicar para qualquer rede, principalmente quando temos as condições especiais descritas acima. E nelas temos os eventos extremos: desastres e emergências. Nesse momento, podemos cartografar.

Em nossas pesquisas sobre o tema, entendemos que, como a operacionalidade desse fluxo social está entregue à dupla delegação de redes de gestão e sociotécnicas, e que elas buscam na maioria das vezes submeter as redes menores do fluxo social, mesmo que estas últimas sejam mais amplas e rizomáticas, faz-se necessário tornar visíveis essas redes menores. E que, em muitos casos, é necessário através de dispositivos de tecnologia social, estabilizá-las para que não esfarelem ou sejam absorvidas em suas potências pelas redes da dupla delegação.

Dessa forma, foi concebida toda essa linha de pesquisa-intervenção que se manifesta em encontros, artigos, pesquisas, seminários e cursos de formação. Nela, o projeto De Nosso Território Sabemos Nós (OLIVEIRA et al, 2021) em territórios-piloto, nos bairros do Caleme (Teresópolis) e Córrego D’Antas (Nova Friburgo) conduzido pelos pesquisadores liderados pela Fiocruz, associações de moradores dessas localidades, e com o apoio das gestões desses municípios, se propõe o desenvolvimento de um dispositivo em aderência com as comunidades locais em contraponto às desaderências das ações duplamente delegadas, que ficaram expostas pelo desastre das cidades serranas de 2011: iniciativas estatais que visavam a requalificação urbana e territorial nessas localidades, demolindo residências e reconstruindo habitações em outras localidades, no modelo de conjuntos habitacionais, esfacelando o sentimento de pertencimento ao lugar, promovendo a sua desterritorialização.

A desaderência promovida pelo atual modelo de desenvolvimento e dela dependente, numa perspectiva macro hegemônica, pode ser chamada de globalização. No entanto, o que parece geral e global sempre se diferencia quando territorializado, seja em um país desenvolvido ou não, seja em um país do sul global ou de um país do norte global, em que emergem linhas abissais de diferenciação, como define Boaventura Santos (2007). Segundo este autor, numa perspectiva contra-hegemônica, a sua diferenciação exige uma nova epistemologia, ou constelações de epistemologias, para possibilitar a sua compreensão e superação. Conjunto de epistemologias, que simétricas em seus estudos e manifestações, também exige, na busca de maior aderência, uma ecologia dos saberes.

A aparente inércia cidadã - que significa apenas que a mobilização comunitária está caminhando em uma direção invisível - resultado de anos de aplicação de dispositivos formadores de consciências duplamente delegadas - exige, para que a simetria cognoscitiva aconteça, que a circulação de saberes se transforme num dispositivo de dispositivos para que a dupla delegação dominante não se imponha como única opção (SCHWARTZ; BURRIVE, 2010). Uma estratégia para enfrentar as condições de incerteza de nossa época, para não desperdiçar experiências sociais disponíveis e nem classificar como impossíveis experiências sociais emergentes (SANTOS, 2003). Para que, assim, os moradores possam se apropriar de seu próprio território, do ponto de 
vista que sempre pertenceu à gestão-academia, utilizando os conhecimentos disciplinares da geografia, da demografia, e do ordenamento territorial como conhecimentos auxiliares e não como conhecimentos determinantes de seus modos de vida. E criar a possibilidade de reverter na produção dos mapas sociais a sua direção dominante, técnica e sempre orientada por interesses de poder e de Estado, na direção do que é considerado relevante pelas próprias comunidades.

Concretamente, para construção de um grupo de trabalho e formação da Comunidade Ampliada de Pesquisa-Intervenção (CAPI), , realizamos nas comunidades do Caleme e Córrego Dantas, reuniões com as Associações de Moradores e outras lideranças da comunidade, que apoiaram a execução do projeto e abrigaram a proposta cedendo espaço para que ocorressem os encontros. A construção da CAPI em cada território se deu de maneira diferente, respeitando as singularidades locais, com a realização de quatro oficinas para desenvolvimento das cartografias comunitárias, sempre aos sábados, uma vez por mês (de agosto a novembro de 2019). A associação de Córrego D’Antas tem sede própria, enquanto o Caleme se utiliza do espaço anexo da principal igreja católica do bairro para realização de seus encontros, onde foram realizadas as oficinas. Com antecipação, os encontros eram divulgados na comunidade, através de cartazes e contatos diretos com lideranças para multiplicação da informação. Participação em média de vinte pessoas entre moradores, profissionais ligados as Secretarias Municipais da Saúde, Defesa Civil, Desenvolvimento Social e Ambiente, além do grupo de pesquisadores. As oficinas sempre se iniciavam com uma dinâmica em roda e, no final do encontro, voltava-se à roda para um fechamento.

O projeto, apresentado pelos pesquisadores e consensuado com os moradores e técnicos e gestores mais próximos, se estrutura a partir de quatro dispositivos: cartografia social, produção de índices de vulnerabilidade socioambiental ${ }^{6}$, censo comunitário vivo e projeto memória, que convergem para um aplicativo de comunicação comunitária. Algumas dessas ações estão mais adiantadas do que outras em função das dinâmicas territoriais e, também, da pandemia que dificultou as idas a campo desde março de 2020. A proposta consensuada compreende que as ações devem apoiar não só às comunidades, mas também a um novo olhar da gestão para com os territórios, onde o saber local tenha valor para a gestão e vice-versa. Num esforço para constituição e manutenção das chamadas Comunidade Ampliada de Pesquisa-Intervenção locais, onde academia, gestão e comunidade têm os seus saberes reconhecidos, legitimados e em relação simétrica.

\section{5. À guisa de posfácio}

A partir de agora, temos evidentemente um mundo permanentemente enredado, consequência da explosão das redes. Mas não nos esqueçamos de Bruno Latour e Gabriel Tarde: sempre foram redes. Mesmo que, em alguns locais, pareçam invisíveis por miopia de nosso olhar duplamente delegado.

6 Discussão que pode ser acompanhada no artigo Metodologias Participativas, referente à Oficina 6 . 
Uma das principais características que se acredita possuir uma rede é que nela todos os seus integrantes têm o mesmo valor (real e virtual) e, por isso, eles desfrutam de conhecimentos que são simétricos entre si. A valorização da vida, em um ambiente de rede, não pode ser uma abstração, ela precisa passar por cada ser que a compõe. Essa postura ética, estética, política e epistemológica que se acredita estar nas redes precisa se generalizar por causa da generalidade da espécie humana e de seus desafios expresso pela vivência de seus desastres. Somos muitos e é preciso encontrar um pensamento-ação que valorize a diferença de cada ser, para que a igualdade da abstração (vida, sociedade, natureza, humanidade), não os faça ficar invisíveis, que no primeiro momento significa exclusão e, no extremo, extermínio.

A vivência e disposição dessas comunidades que lutaram pela sua sobrevivência, nos mais variados desastres que se seguiram na última década e que seguem buscando inovar em sua relação com a gestão municipal e os conhecimentos instituídos, indicam caminhos potentes para toda a cidade onde estão inseridos, renovando inclusive a produção de conhecimento em rede. Essa experiência foi expandida em sua comunicabilidade durante o II Seminário de Desnaturalização de Desastres e Mobilização Comunitária com oficinas sobre quem são os atingidos no Brasil, sobre a interseccionalidade e megaprojetos, além das mesas e oficinas (figuras 2, 3 e 4) dedicadas aos novos saberes da experiência de profissionais ligados à fronteira da relação gestão-comunidades e dos próprios movimentos comunitários nas mesas 3, 4, 5 e 6. (figura 5).

Figura 2: Facilitação Gráfica da Oficina Quem São os Atingidos.

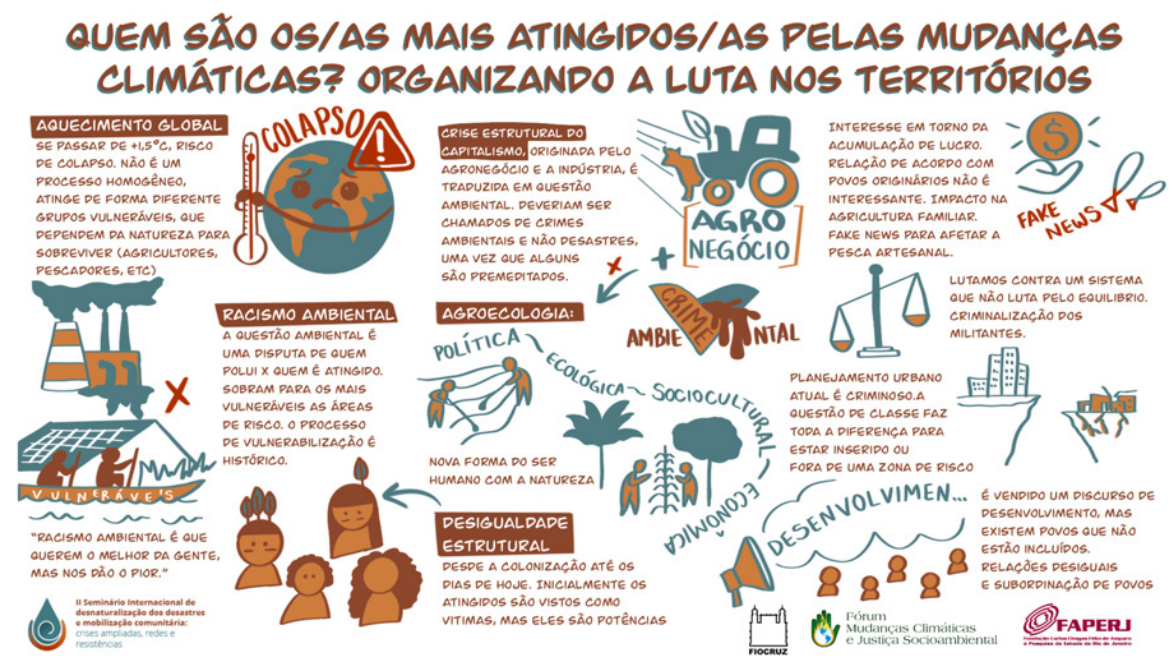

Fonte: Céu Azul Facilitação, II Seminário Internacional de Desnaturalização de Desastres 
Figura 3: Facilitação Gráfica da Oficina Interseccionalidade e Megaprojetos.

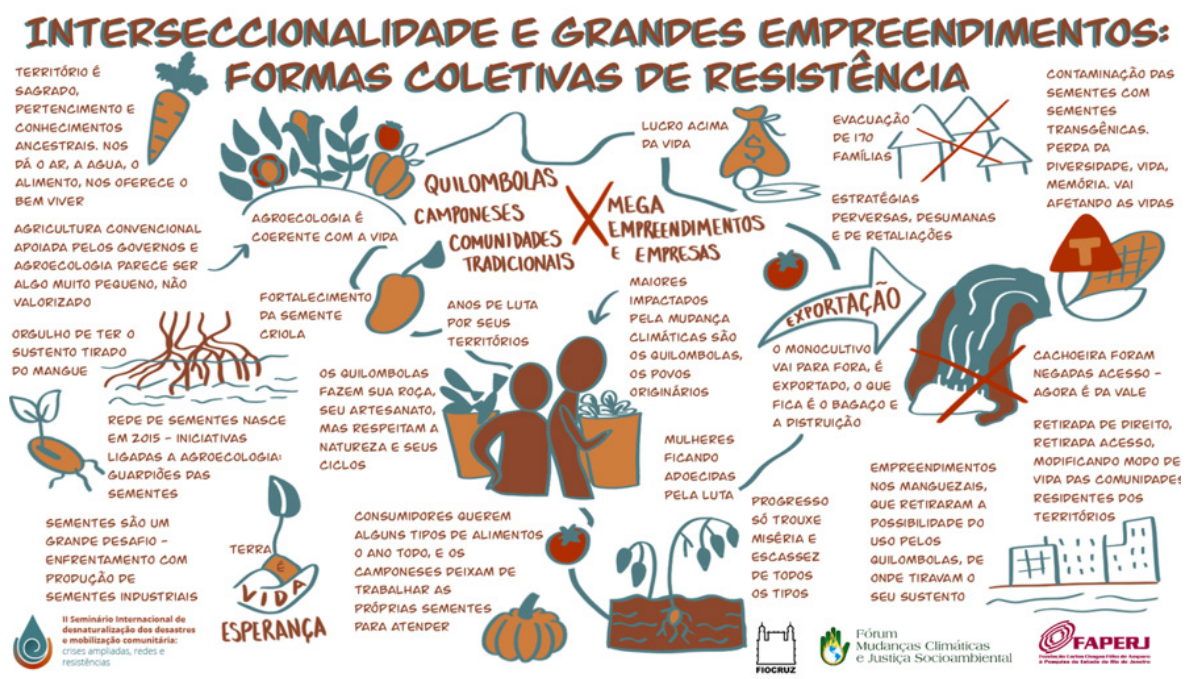

Fonte: Céu Azul Facilitação, II Seminário Internacional de Desnaturalização de Desastres

Figura 4: Facilitação Gráfica da Oficina Vivências do Trabalho em Saúde nas emergências e desastres.

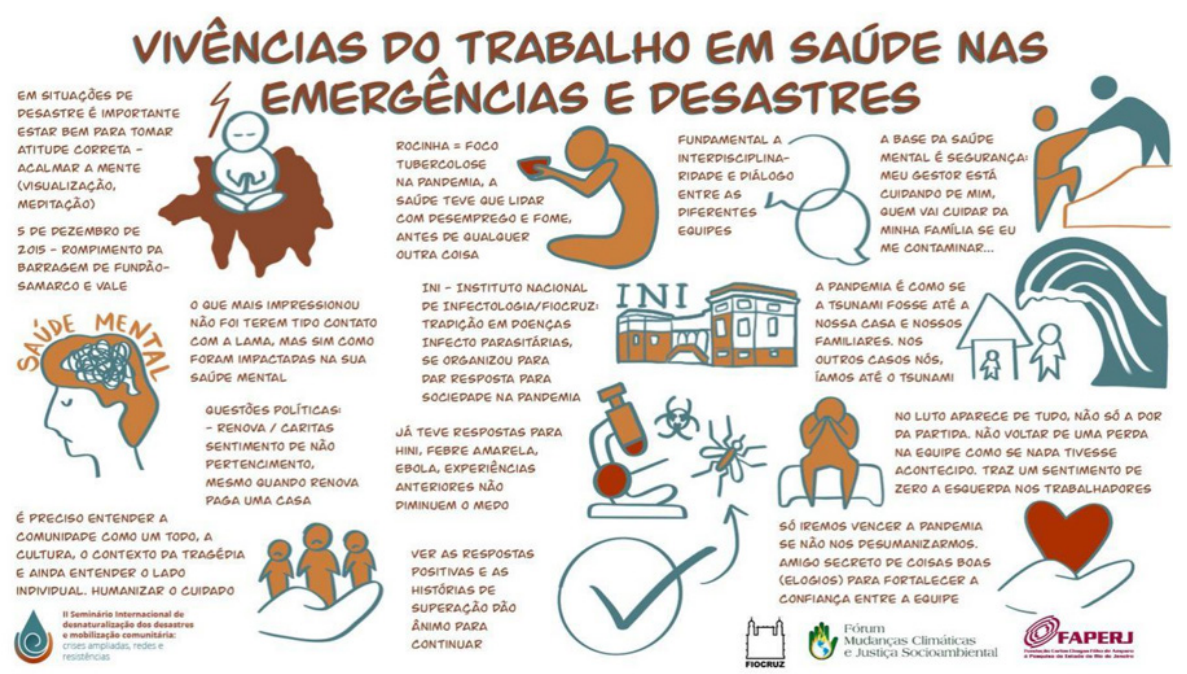

Fonte: Céu Azul Facilitação, II Seminário Internacional de Desnaturalização de Desastres. 
Figura 5: Programação do II Seminário Internacional de Desnaturalização de Desastres e Mobilização Comunitária: Crises ampliadas, Redes e Resistências.

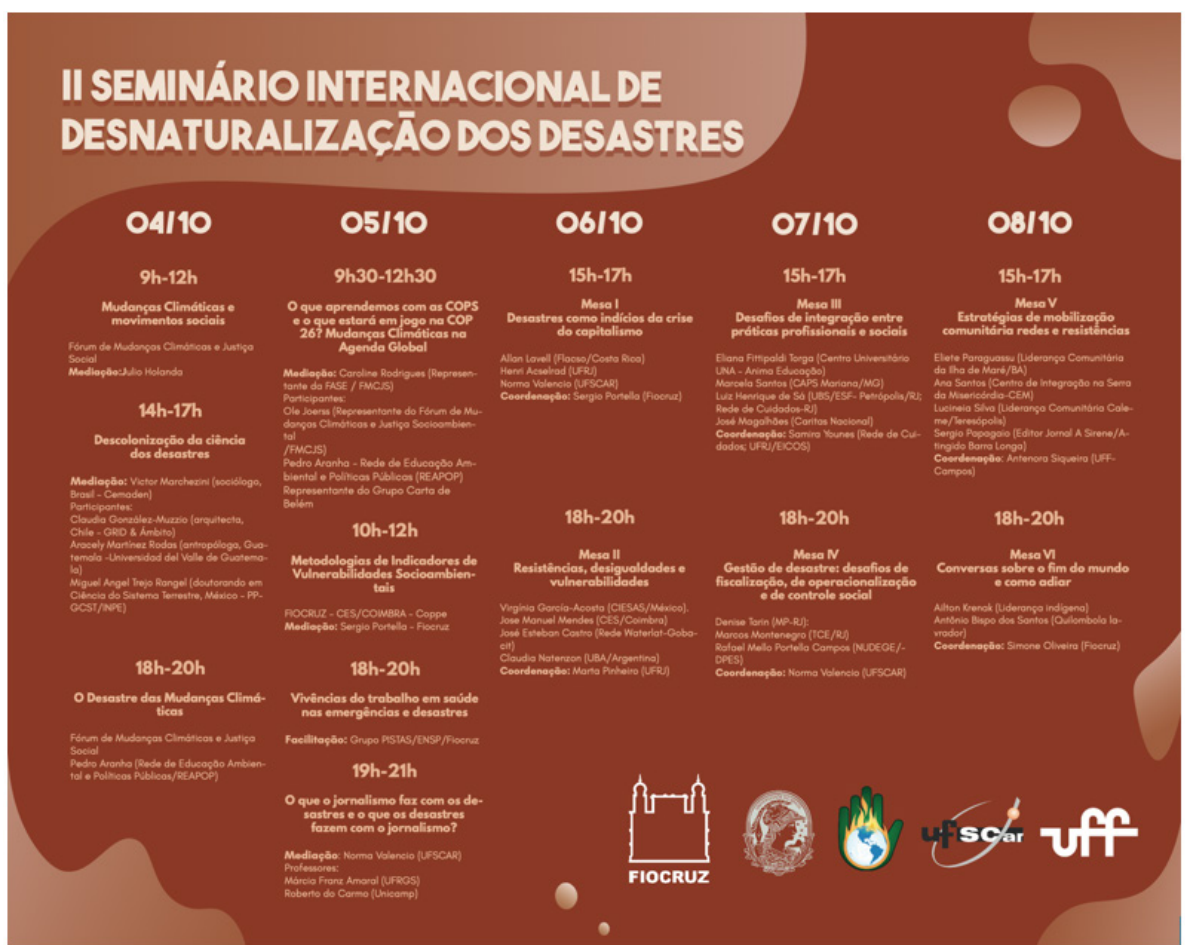

Fonte: II Seminário Internacional de Desnaturalização de Desastres

Em sua horizontalidade, as redes locais são sempre muito rentes ao chão. Mas, mesmo sendo horizontais existe uma topologia das redes, lideranças, descolamentos, protuberâncias. Ironicamente é dessa topologia que nascem as ilusões do conhecimento-árvore! Devemos ignorar essa topologia? Nada deve ser ignorado se queremos enfrentar a volatilidade das redes. Enfrentar a sua volatilidade é, na verdade, respeitá-la. Trabalhar por uma jardinagem de redes-arbustos. Trabalhar pelo pigmento certo para atingir o efeito de cor esperado, por uma pedagogia das redes, onde os sistemas de defesa civil, de educação e de saúde podem ser aliados poderosos. As dificuldades impostas pela pandemia da Covid-19 mais uma vez é exemplo para o bem e para o mal: comunidade integrada e vacinada produzem baixa contaminação e controle pandêmico. O reverso também é verdadeiro.

Estamos diante da necessidade de uma tecnologia social nano que seja capaz de dar visibilidade às redes comunitárias, estabilizando-as, mesmo que momentaneamente, evitando que na combinação das redes de gestão e sociotécnicas, se olhe para as redes comunitárias como uma massa informe, desprovida de laços e de saber (como se isso fosse possível, a ilusão da essencialidade do caule para além das infinitas conexões rizomáticas da floresta). Sem isso, nossas dificuldades diante dos desastres, emergências e mudanças climáticas serão devastadoras. Contra-atacamos essa tendência porque todas as vidas importam! 


\section{Referências}

AGUNIN, A. G.; HIDAlGO, C.; NATENZON, C. E. Producción de conocimiento en redes interdisciplinarias con inclusión de actores sociales: estudio de caso. Revista Pueblos y fronteras digital, v. 6, n. 9, junio-noviembre, p. 68-96, 2010.

BISPO, A. Para a geração neta afrodescendente e afrodiaspórica. In: Cartas para o bem viver/ COSTA, S L \& XUCURU-KARIRI, R (orgs). Salvador: Boto-cor-de-rosa livros arte e café, p. 252-254, 2020.

CASTELLS, M. Redes de indignação e esperança: movimentos sociais na era da internet. Rio de Janeiro: Zahar, 2013.

DELEUZE, G.; GUATTARI, F. Mil platôs - capitalismo e esquizofrenia. Rio de Janeiro: Ed. 34, 1996.

ELIAS, N. A Sociedade dos Indivíduos. Rio de Janeiro, Zahar, 1994.

FOUCAULT, M. Do governo dos vivos: Curso no Collège de France, 1979-1980: aulas de 9 e 30 de janeiro de 1980/Michel Foucault. São Paulo: Centro de Cultura Social, 2009.

KOPENAWA, Davi; ALBERT, Bruce. A Queda do Céu. Companhia das Letras, 2016.

KRENAK, A. Para quem quer cantar e dançar para o céu. In Cartas para o bem viver/A. COSTA, S L \& XUCURU-KARIRI, R (orgs). Salvador: Boto-cor-de-rosa livros arte e café, p.20-22, 2020.

LATOUR, B. A esperança de Pandora. Bauru: Edusc, 2001.

LAVELL, A. Entrevista Allan Lavell em Seminario Internacional Ciencias Sociales y Riesgo de Desastres en America Latina: un encuentro inconcluso, setembro, 15 a 17. Buenos Aires, 2015.

LÉVI-STRAUSS, C. O cru e o cozido. Mitológicas 1. São Paulo, CosacNaify, 2004. 442 páginas.

OLIVEIRA, S. S., PORTELlA, S., YOSHIKAWA , C. T., LOBOSCO, D., DIAS, L. F., DE OLIVEIRA, T. C.. De Nosso Território Sabemos Nós: experiência de cartografia social para emergências e desastres. Cien Saude Colet [periódico na internet] (2021/ Mai). Está disponível em: http://www.cienciaesaudecoletiva.com.br/artigos/de-nosso-territorio-sabemos-nos-experiencia-de-cartografia-social-para-emergencias-e-desastres/ 18085 
OLIVEIRA, S.; PORTELLA, S.; SIQUEIRA, A.; FREITAS, M. Desnaturalização dos desastres e mobilização comunitária: redes e rodas. Revista Ciência \& Trópico, v.40, n. 1, 2016.

PORTELLA, S; NUNES, J. A. Populações serranas excluídas, cidades insustentáveis: o enigma da participação pública. Rev. Ciência \& Saúde Coletiva, v. 19, n. 1, p. 42234228, 2014.

PORTELLA, S.; OLIVEIRA, S.S.; DUTRA, R. Tudo é água... e participação social Labor \& Engenho, v.9, n.4, p.66-75, out./dez. 2015.

SANTOS, B. S. Para além do Pensamento Abissal: das linhas globais a uma ecologia de saberes. Revista Crítica de Ciências Sociais, v. 78, p. 3-46, out. 2007.

SANTOS, B. S. Reconhecer para libertar: os caminhos do cosmopolitanismo multicultural. Rio de Janeiro: Civilização Brasileira, 2003.

SANTOS, Milton. O retorno do territorio. En: Observatorio Social de América Latina. Ano 6, 16. Buenos Aires : CLACSO, 2005.

SIMARD, S. Climate Change and Variability. Publisher: Sciyo, 2010.

TARDE, G. A Opinião e a Multidão, Lisboa: Publicações Europa América, 1991.

TARDE, G. As Leis sociais: um esboço de Sociologia/Gabriel Tarde;- Niterói: Editora da UFF, 2011.

VALENCIO, N. Desastres, ordem social e planejamento em Defesa Civil: o contexto brasileiro. Saúde e Sociedade, São Paulo, v. 9, n. 4, p.748-762, dez. 2010.

VIEZZER, Moema; GRONDIN, Marcelo. Abya Yala: Genocídio, resistência e sobrevivência dos povos originários das Américas. Rio de Janeiro: Bambual Editora, 2021. 